\title{
The effects of acetylation on properties of flax fibre and its polypropylene composites
}

\author{
A. K. Bledzki ${ }^{*}$, A. A. Mamun ${ }^{1}$, M. Lucka-Gabor 1, V. S. Gutowski \\ ${ }^{1}$ Institut für Werkstofftechnik, Kunststoff- und Recyclingtechnik University of Kassel, Mönchebergstr. 3, \\ D-34109 Kassel, Germany \\ ${ }^{2}$ CSIRO Manufacturing \& Infrastructure Technology, Novel Materials \& Processes, PO Box 56, Highett Melbourne, \\ Victoria 3190, Australia
}

Received 19 February 2008; accepted in revised form 13 April 2008

\begin{abstract}
Flax fibre was modified with acetylation. The influence of the acetylation on the structure and properties of flax fibre were investigated as well as modified flax fibre reinforced polypropylene composites were also prepared. The catalyst was used to accelerate acetylation reaction rate. Flax fibre was characterised after modification. Surface morphology, moisture absorption property, components content, degree of polymerisation, crystallinity of cellulose and thermal stability of flax fibres were studied. Due to acetylation, the flax fibre surface morphology and moisture resistance properties improved remarkably. Flax fibre (modified and unmodified) reinforced polypropylene composites were fabricated with $30 \mathrm{wt} \%$ fibre loading. The mechanical properties were investigated for those composites. Tensile and flexural strengths of composites were found to increase with increasing degree of acetylation up to $18 \%$ and then decreased. Charpy impact strengths of composites were found to decrease with increasing degree of acetylation. Owing to addition of coupling agent (maleated polypropylene - $\mathrm{MAH}$ ), the tensile and flexural strength properties were found to increase in between 20 to $35 \%$ depending on degree of acetylation.
\end{abstract}

Keywords: reinforcements, flax fibre, acetylation, fibre characterisation, mechanical properties

\section{Introduction}

A better understanding of the chemical composition and surface adhesive bonding of natural fibre is necessary for developing natural fibre-reinforced composites. The composition of natural fibres includes cellulose, hemicellulose, lignin, pectin, fat, waxes and water soluble substances [1-3]. The composition may differ with the growing condition and test methods even for the same kind of fiber [4]. Cellulose is a semicrystalline polysaccharide with a large amount of hydroxyl group in cellulose, giving hydrophilic nature to natural fibre when used to reinforce hydrophobic matrices; the result is a very poor interface and poor resistance to moisture absorption [5]. Hemicellulose is strongly bound to cellulose fibrils presumably by hydrogen bonds. Hemicellulosic polymers are branched, fully amorphous and have a significantly lower molecular weight than cellulose. Because of its open structure containing many hydroxyl and acetyl groups, hemicellulose is partly soluble in water and hygroscopic [6]. Lignins are amorphous, highly complex, mainly aromatic, polymers of phenylpropane [7] units but have the least water sorption of the natural fibre components [6].

The natural fibre exhibits a high hydrophilicity due to attraction or interaction between the hydroxyl groups of fibre components and water molecules. The interactions between fibre and water originate from the non-crystalline region and extend to the 
crystalline region. The uptake of water by hygroscopic substance such as cellulose and hemicellulose is a hydration process involving accessible hydroxyl groups. Water molecule absorbed by cellulose molecule form cellulose hydrate and the reaction is exothermic, which provide the driving force for further absorption $[8,9]$. The high moisture sensitivity of lignocellulosic fibre causes the dimensional instability and limits the use of fibre as reinforcement in composite materials. Low interfacial properties between fibre and polymer matrix often reduce their potential as reinforcing agents due to the hydrophilic nature of natural fibres; chemical modifications are considered to optimize the interface of fibres. Generally, chemical coupling agents are molecules possessing two functions. The first function is to react with hydroxyl groups of cellulose and the second is to react with functional groups of the matrix [10].

The moisture absorbed by the fibres can be reduced by chemical modifications of fibres such as acetylation, methylation, cyanoethylation, benzoylation, permanganate treatment, acrylation etc. [11-15].

Acetylation of natural fibres is a well-known esterification method causing plasticization of cellulosic fibres. Polymer hydroxyl groups of the cell wall with acetyl groups, modify the properties of these polymers so that they become hydrophobic which could stabilize the cell wall against moisture, improving dimensional stability and environmental degradation [16].

In addition, acetylation is one of the most studied reactions of lignocellulosic materials. Cellulose acetate was discovered in 1865 , and partially acetylated cellulose products were commercialised as acetate rayon fibres and cellulose acetate plastics in the early 1900s. The first attempt of acetylating wood flour and sawdust took place in 1928. The principle of the method is to react the hydroxyl groups $(-\mathrm{OH})$ of the fibre constituents with acetyl groups $\left(\mathrm{CH}_{3} \mathrm{CO}-\right)$. The reaction is known to proceed to full esterification of all the three hydroxyls of anhydro-D-glucose when it is carried out in a homogeneous phase (i.e. when cellulose is dissolved), but in the case of fibres and wood where the reaction is heterogeneous. So it is thought to esterify all hydroxyl groups of the fibre. Hence, a highly non-uniform product may be obtained. In these cases, it is necessary to use catalyst speeding up acetylation process. There are large number of catalysts that have been used in the past, including sulphuric acid, pyridine, potassium and sodium acetate, gamma-rays, etc. However, the use of catalysts poses many problems. Strong mineral acids or acid salts are known to cause hydrolysis of cellulose resulting in damage of the fibre structure [17]. So, selection and optimization of catalyst is important for the acetylation of lignocellulosic fibre. The hydroxyl groups that react are those of the minor constituents of the fibre, i.e. lignin, hemicelluloses, and those of amorphous cellulose. That is because the hydroxyl groups in crystalline regions with close packing and strong interlock bonding are completely inaccessible [18].

Reduction of about $50 \%$ of moisture uptake for acetylated jute fibres and of up to $65 \%$ for acetylated pine fibres has been reported in the literature [10].

Seena et al. investigated the effect of acetylation in banana fibre reinforced phenol formaldehyde composites and reported that the tensile strength, tensile modulus and impact strength are found to improve compared to non treated banana fibre composites [12].

Liu et al. studied the effect of acetylation in natural fibre composites (cotton, rayon, wood with polystyrene as matrix) and they showed, by using the micro-debonding test that acetylated fibres had increased interfacial shear strength. Furthermore, they reported that acetylation increased the surface free energy of the fibres [19].

Zafeiropoulos et al. investigated aectylation of flax, hemp and wood fibre and resulted in a removal of non-crystalline constituents of the fibres, altered the characteristics of the surface topography, changed the fibre surface free energy and improved the stress transfer efficiency at the interface [17, 20].

In the present work a detailed investigation has been carried out on the effect of acetylation on the flax fibre properties in terms of fibre composition, fibre surface, degree of crystallinity, degree of polymerisation, moisture absorption and thermal stability, as well as, a detailed investigation has been investigated on the effect of acetylation of flax fibre on the flax fibre reinforced polypropylene composites properties. 


\section{Experimental}

\subsection{Materials}

Green flax fibre $(6-8 \mathrm{~mm})$ was obtained from Mühlmeier GmbH, Germany.

Acetic anhydride, toluene, perchloric acid, sodium hydroxide, hydrochloric acid, ethanol, sulphuric acid, acetic acid, sodium chlorite, acetone, iodine, potassium iodine, sodium sulphate, sodium thiosulphate were collected from Merck KgaA, Darmstadt, Germany. All chemicals were analytical grade.

A commercially available maleic anhydridepolypropylene copolymer (Licomont AR 504 FG) with an acid number of $37-43 \mathrm{mg} \mathrm{KOH} / \mathrm{g}$ was used as a coupling agent. It was obtained from Clariant Corporation, Frankfurt, Germany. Its softening point was $153^{\circ} \mathrm{C}$ and density was $0.89-0.93 \mathrm{gm} / \mathrm{cm}^{3}$. It accounted for $5 \%$ of the weight percentage of fibre.

\subsection{Methods}

\subsubsection{Acetylation process}

The flax fibres were soaked in demineralised water for an hour, filtered and placed in a round bottom flask, containing acetylating solution. Acetylating solution consist of $250 \mathrm{ml}$ toluene, $125 \mathrm{ml}$ acetic anhydride and a small amount of catalyst perchloric acid $(60 \%)$. The process temperature of acetylation was $60^{\circ} \mathrm{C}$ and duration was 1 to 3 hour. After modification, the fibre was washed periodically with distilled water until acid free. Finally modified flax fibres were air dried for certain time before investigation.

\subsubsection{Modified fibre characterisation}

\section{Degree of acetylation}

The acetyl groups' content was measured by saponification methods. Modified flax fibre was saponified by $0.5 \mathrm{~N}$ sodium hydroxide solution. After saponification, the excess alkali was titrated by $0.5 \mathrm{~N}$ hydrochloric acid. Similar method has been considered for untreated flax fibre and the degree of acetylation calculated from the difference.

\section{Extractibles content}

The air dried sample of $5 \mathrm{~g}$ was weighed in an extraction thimble and placed in Soxhlet extraction unit. A mixture of ethanol and toluene was used as solvent and extraction process continued for a period of five hours. After extraction the sample was rinsed with ethanol and hot water and dried up to constant weight at the temperature of $60^{\circ} \mathrm{C}$. The extractibles were calculated as a percentage of the oven dried test sample and the method has been repeated for each sample.

\section{Lignin content}

Two grams of extracted sample were placed in a flask and $15 \mathrm{ml}$ of $72 \%$ sulphuric acid was added. The mixture was stirred frequently for two and half hours at $25^{\circ} \mathrm{C}$ and $200 \mathrm{ml}$ of distilled water were added to the mixture. Then the mixture was boiled for next two hours and cooled. After 24 hours, the lignin was transferred to the crucible and washed with hot water repeatedly until becoming acid free. The collected lignin was dried at $105^{\circ} \mathrm{C}$ and cooled down in desiccator and weighed. The drying and weighing were repeated until constant weight.

\section{Holocelluloses content}

Three grams of air dried flax fibre were weighed and placed in an Erlenmeyer flask and then, $160 \mathrm{ml}$ of distilled water, $0.5 \mathrm{ml}$ of glacial acetic acid and $1.5 \mathrm{~g}$ of sodium chloride were added successively. The flask was placed in water bath and heated up to $75^{\circ} \mathrm{C}$ for an hour and then additional $0.5 \mathrm{ml}$ of glacial acetic acid and $1.5 \mathrm{~g}$ of sodium chloride were added. The additions of acetic acid and sodium chloride were repeated two times hourly. The flask was placed in an ice bath and cooled down below $10^{\circ} \mathrm{C}$. The holocellulose was filtered and washed with acetone, ethanol and water respectively and at the end, sample was dried in oven at $105^{\circ} \mathrm{C}$ before weighed.

\section{$\alpha$-cellulose content}

Two grams of holocellulose were placed in a beaker and $10 \mathrm{ml}$ of sodium hydroxide solution $(17.5 \%)$ was added. The fibres were stirred up by glass rod so that they could be soaked with sodium 
hydroxide solution vigorously. Then sodium hydroxide solution was added to the mixture periodically (once every five minutes) for half an hour and the mixture temperature was kept at $20^{\circ} \mathrm{C}$. About $33 \mathrm{ml}$ of distilled water was added in the beaker and kept it for an hour. The holocellulose residue was filtered and transferred to the crucible and washed with $100 \mathrm{ml}$ of sodium hydroxide (8.3\%), $200 \mathrm{ml}$ of distilled water, $15 \mathrm{ml}$ of acetic acid (10\%) and again water successively. The crucible with $\alpha$-celluloses was dried and weighed.

\section{Hemicellulose content}

The content of hemicelluloses of flax fibre was calculated from Equation (1):

Hemicelluloses $=$ Holocellulose $-\alpha$-celluloses

\section{Degree of polymerisation of cellulose}

The molecular weight of cellulose was measured by capillary viscometry according to the Cuoxam method. It was observed that the cellulose was not completely soluble in cuoxam solution. Before measurement, the solution was filtered and viscosity was measured. This method was performed at room temperature and this method is valid for the viscosity range of $0.1<\eta<2.0$. Temperature and damage correction factors have been considered during calculation. The average molecular weights (DP $=$ degree of polymerisation) were calculated by using Equation (2):

$\mathrm{DP}=\eta /[1+(0.28 \cdot \alpha)] \cdot(1000 / 6.1 C)$

where $\eta$ is the specific viscosity, $C$ is the concentration of cellulose materials in cuoxam solution.

\section{Degree of crystallisation of cellulose}

The crystallinity of cellulose was determined according to iodine absorption method. Treated flax fibres $(0.3 \mathrm{~g})$ were taken in a beaker and $2 \mathrm{ml}$ of iodine solution ( $10 \mathrm{~g}$ iodine and $80 \mathrm{~g}$ potassium iodide in $100 \mathrm{ml}$ of demineralised water) and $100 \mathrm{ml}$ of saturated sodium sulphate solution were added. The temperature was adjusted to $20^{\circ} \mathrm{C}$ before adding sodium sulphate solution and then the beaker was kept in the dark place for an hour. The remaining iodine in solution was determined by titration with $0.03 \mathrm{M}$ sodium thiosulphate (starch as indicator).

\section{Thermo gravimetric analysis (TGA)}

The thermal gravimetric analysis of treated and untreated flax fibres were conducted by thermal gravimetric analyser (TGA-Model TG 50), supplied by TA Instrument. $20 \mathrm{mg}$ sample of each type of fibre has been taken for analysis. The samples were heated up; steadily at a rate of $20 \mathrm{~K} / \mathrm{min}$ from 25 to $500^{\circ} \mathrm{C}$ in nitrogen medium. To get perfection, analysis has been done two times for each sample.

\section{Scanning electron microscope}

The morphology of treated and untreated flax fibres were investigated using scanning electron microscope (SEM), MV2300, CamSan Electron Optics. Flax fibres were fixed on metal surface with special adhesive and sputter coated with gold before investigation.

\subsubsection{Processing of Composites by mixer-injection moulding}

Treated or untreated flax fibres with polypropylene were mixed by high speed cascade mixer (Henschel heat-cooling mixer system, type HM40-KM120). Flax fibres were dried at $80^{\circ} \mathrm{C}$ in an air circulating oven for 24 hours (moisture content $<1 \%$ ) before mixing. The flax fibre at $30 \%$ proportion and polypropylene was placed into hot mixer and heated to the melting temperature of polypropylene $\left(173^{\circ} \mathrm{C}\right)$ and then hot agglomerate granules were transferred to the cool mixer where hot agglomerate granules were cooled down to room temperature by the cold water. Then cold agglomerate granules were dried again $\left(80^{\circ} \mathrm{C}, 24\right.$ hours) before the sample preparation by injection moulding process. Test samples were prepared from dried agglomerate by injection moulding process at temperature zone $150-180^{\circ} \mathrm{C}$, mould temperature of $80^{\circ} \mathrm{C}$ with an injection pressure of $20 \mathrm{kN} / \mathrm{mm}^{2}$.

\subsubsection{Characterization of composites}

Tensile, flexural and impact tests were carried out for characterization of composites. Tensile and flexural tests were performed at a test speed of 
$2 \mathrm{~mm} / \mathrm{min}$ according to EN ISO 527 and EN ISO 178 using a Zwick UPM 1446 machine. All tests were performed at room temperature $\left(23^{\circ} \mathrm{C}\right)$ and at a relative humidity of $50 \%$. Charpy impact test was carried out using 10 notched samples according to EN ISO 179 using Zwick Charpy impact machine. In each case a standard deviation $<5 \%$ (drop weight) was used to calculate the Charpy impact strength.

\section{Results and discussion}

\subsection{Acetylation process}

\subsubsection{Effects of catalyst}

The flax fibres modification was conducted with varying percentage of catalyst at $60^{\circ} \mathrm{C}$ temperature. The acetylation process was studied with and without catalyst. It was observed that the acetylation reaction rate increased in the presence of catalyst and without catalyst the reaction kinetic of acetylation process was slower and dependent on fibre moisture content which is illustrated in Figure 1 [17]. It was found that by addition of $0.026 \%$ catalyst in acetylation process, the reaction rate increased and it was nearly triple after one hour. The degree of acetylation of flax fibre could reach up to $40-45 \%$ in the presence of $0.052 \%$ catalyst in three hours duration. With a catalyst content of more than $0.052 \%$ it is difficult to control acetylation process because the kinetic of reaction is very fast and suddenly damages the fibre.

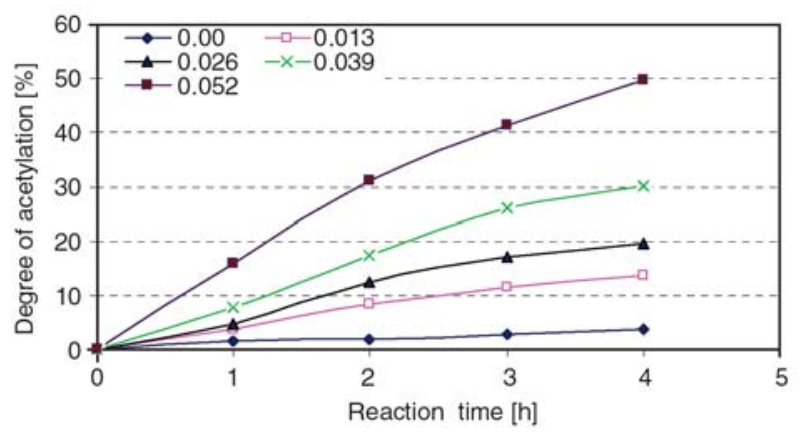

Figure 1. Influence of catalyst concentration on degree of acetylation

\subsection{Fibre characterisation}

\subsubsection{Moisture absorption}

The influence of degree of acetylation of flax fibre on the moisture absorption properties were illus-

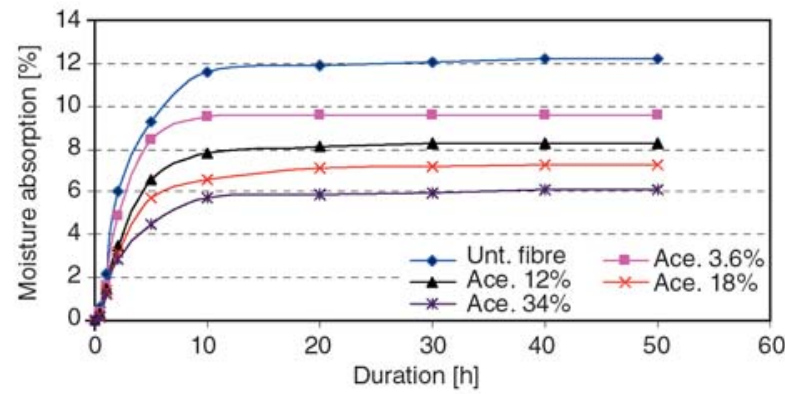

Figure 2. Influence of acetylation of flax fibre on moisture absorption property at $65 \%$ relative humidity

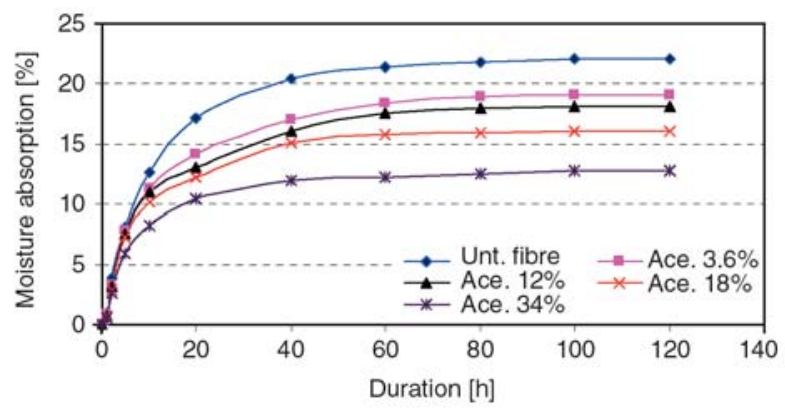

Figure 3. Influence of acetylation of flax fibre on moisture absorption property at $95 \%$ relative humidity

trated in Figure 2 and Figure 3 respectively at different relative humidity $(65,95 \%)$. At the RH of $65 \%$, the $3.6,12,18$ and $34 \%$ degree of acetylated flax fibre respectively showed about $21,32,40$ and $50 \%$ lower moisture absorption properties than untreated flax fibre. At $95 \% \mathrm{RH}$, the 3.6, 12, 18 and $34 \%$ degree of acetylated flax fibre showed about 14, 18, 27 and $42 \%$ lower moisture absorption properties than untreated flax fibre respectively. It was observed that the moisture absorption properties decreased proportionally with increase of acetyl content of fibre which is because of reduction of hydrophilicity of the fibre.

\subsubsection{Fibre components}

The influence of acetylation on the composition of the fibres is shown in the Figure 4. It was observed that the cellulose contents increased gradually until $12 \%$ degree of acetylation which is due to the extraction of lignin and extractibles from fibre and after that the cellulose contents decreased slowly which is because of degradation of cellulose, increased amorphous content and acetylated hemicellulose deposition on the fibre surface [20]. It was also observed that the lignin contents decreased steadily until $34 \%$ acetylation which is because of solubility of lignin and the extractives content 


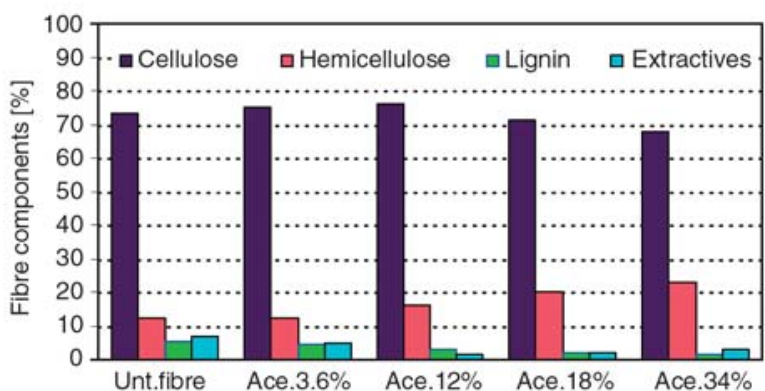

Figure 4. Influence of acetylation of flax fibre on the content of fibre components

decreased till $12 \%$ acetylation and then increased slowly which is because of cellulose degradation. On the other hand hemicellulose contents were found to increase with increasing degree of acetylation.

\subsubsection{Degree of polymerisation and crystallinity of cellulose}

The effects of the acetylation on the degree of polymerisation and crystallinity of cellulose illustrated in Figure 5. It was observed that the degree of polymerisation slowly decreased with increasing degree of acetylation till 18\%. It is because of increase amorphous (low molecular weight acetylhemicellulose) content. After $18 \%$ acetyl content the degree of polymerisation decreased sharply which because of vigorous degradation of cellulose.

From the Figure 5 it is also observed that the degree of crystallinity a little bit increased initially with respect to degree of acetylation which is because of removal of lignin and extractibles. After that the

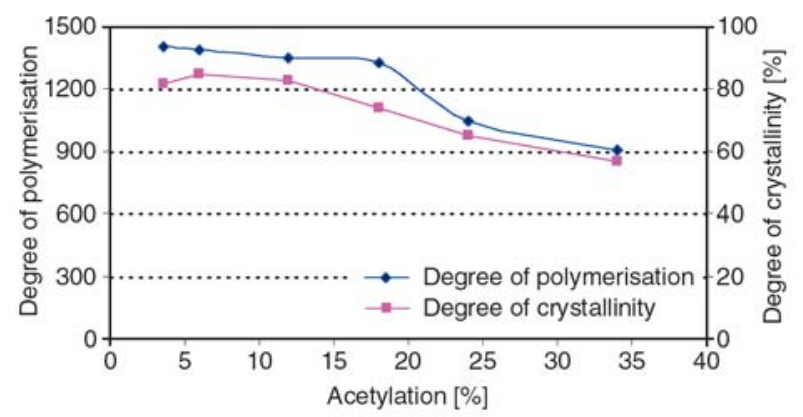

Figure 5. Influence of acetylation of flax fibre on the degree of polymerisation and degree of crystallinity of cellulose degree of crystallinity of cellulose decreased with respect to degree of acetylation which is because of deposition of acetylated amorphous components on cellulose surface [20].

\subsubsection{Thermal stability}

The effect of acetylation of flax fibre on the thermal properties is shown in Table 1. It was observed that the thermal stability improved with increasing degree of acetylation. It was also observed that the degradation temperature of untreated flax is $319^{\circ} \mathrm{C}$. The flax fibre with $34 \%$ acetyl content showed best thermal stability, and the degradation temperature was found to increase to $360^{\circ} \mathrm{C}$ compared to untreated fibre. The increase of thermal stability of acetylated fibre was because of washing out of wax, lignin and hemicellulose from the fibre surface. Simultaneously it was also observed that with increasing degree of acetylation a little portion of acetylated hemicellulose deposited on to the fibre surface in presence of catalyst. Fibre chemical compositions determination is the evidence.

\subsubsection{Morphology}

Surface morphology of treated and untreated fibres is shown in Figure 6. In the Figure 6a, 6b, it was observed that the untreated fibre surface is rough, exhibiting waxy and protruding parts. The surface morphology of treated fibre viewed in Figure 6c, $6 \mathrm{~d}$. On the acetylation treatments the wax and cuticle in the surface is removed by the interaction with acetyl and surface becomes smother. The fibrillation is also found to occur as the binding materials removed and some micropores appear in the treated fibres. It was also observed from Figure 6e, $6 f$ that the higher degree of acetylation the fibrillation increased but fibre damage and crack were also observed.

\subsection{Mechanical properties of composites}

\subsubsection{Tensile properties}

Figure 7 shows the degree of acetylation of flax fibre on tensile properties of composites. Tensile

Table 1. Thermal stable temperature of treated and untreated flax fibre

\begin{tabular}{|l|c|c|c|c|c|c|}
\hline & \multirow{6}{*}{ Untreated } & \multicolumn{5}{|c|}{ Degree of acetylation [\%] } \\
\cline { 3 - 7 } & 319 & 3.6 & $\mathbf{6}$ & $\mathbf{1 2}$ & $\mathbf{1 8}$ & 34 \\
\hline Stable temperature $\left[{ }^{\circ} \mathrm{C}\right]$ & 326 & 329 & 334 & 341 & 360 \\
\hline
\end{tabular}




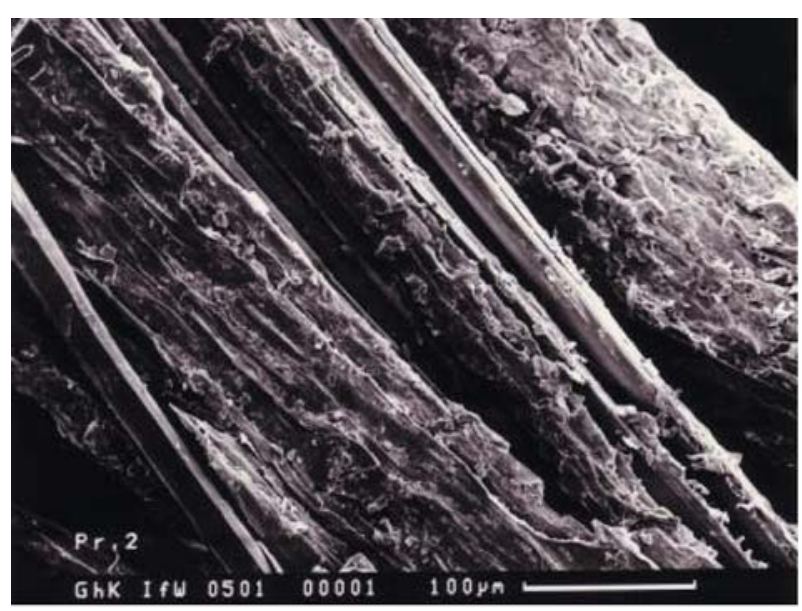

a)
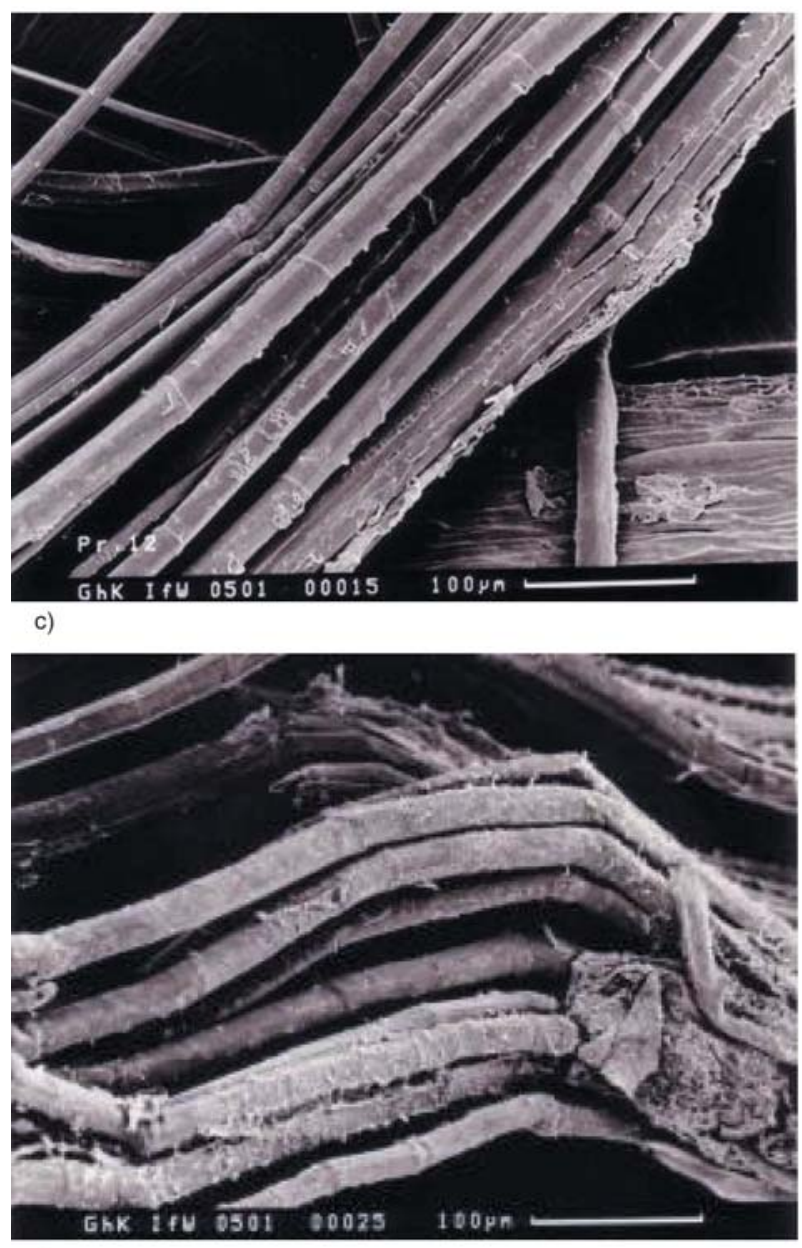

e)

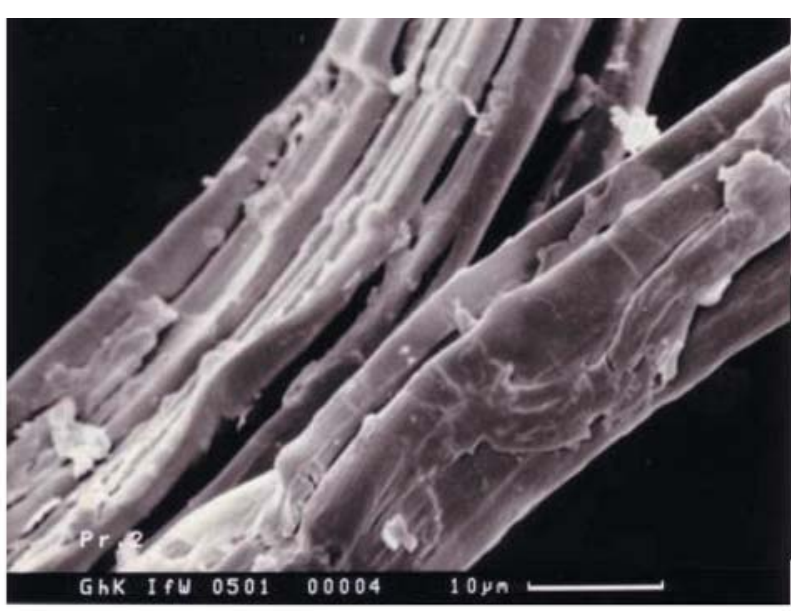

b)

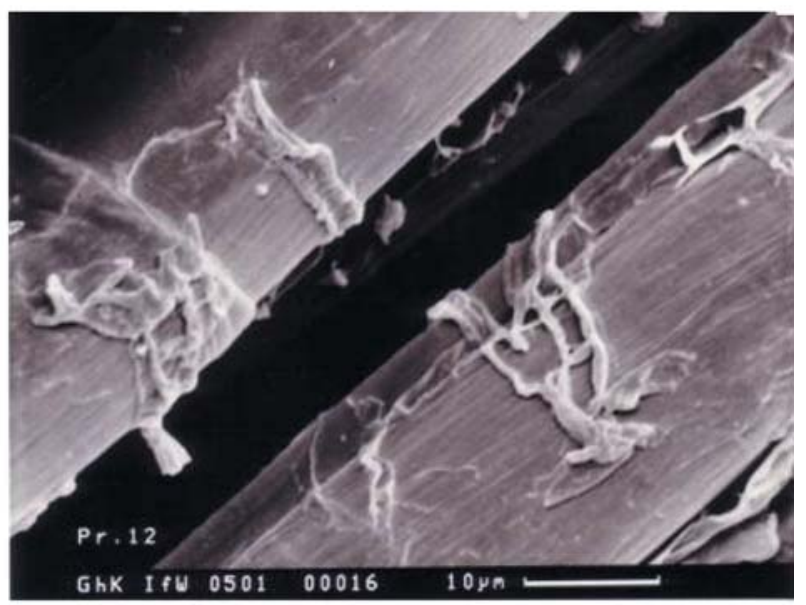

d)

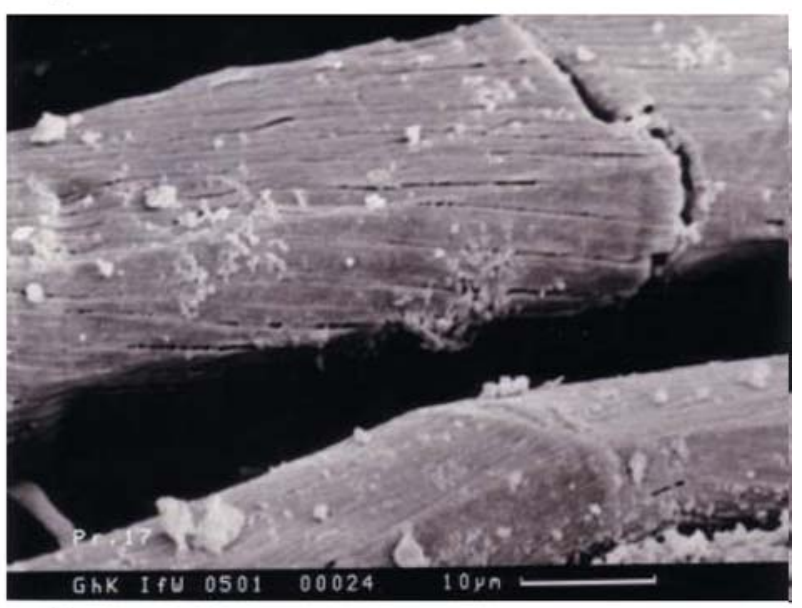

f)

Figure 6. SEM photograph of flax fibre; $(6 a, 6 b)$ untreated flax fibre surface, $(6 c, 6 d)$ acetylated flax fibre at degree of acetylation $18 \%$ and $(6 \mathrm{e}, 6 \mathrm{f})$ fibre damage at high degree of acetylation

strength of composites were found to increase with increasing degree of acetylation up to $18 \%$ and then decreased with further increasing degree of acetylation. The increase in tensile strength could be due to the removal of lignin and extractibles, slight increase in cellulose content and a little portion of hemicellulose converting to acetylated hemicellu- lose. After $18 \%$ acetylation of flax fibre, the composites tensile strength was found to be decrease swiftly. It could be due to the degradation of cellulose and to the introduction of internal cracks in the fibres. It was also noted that the acetylation of flax fibre removed waxy material from fibre surface, increased fibre-matrix interfacial strength and 


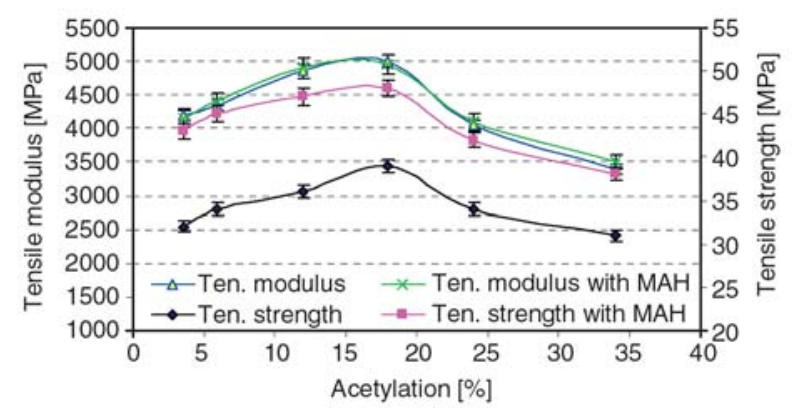

Figure 7. Influence of acetylation of flax fibre on tensile properties of composites

increased surface free energy which are favourable for better properties of composites. With the addition of MAH, the same tendency was observed and the tensile strength of 20 to $35 \%$ improvements was observed respect to degree of acetylation. This is due to the formation of ester bonds between fibre and polypropylene.

\subsubsection{Flexural properties}

Flexural strength is the ability of the material to withstand bending forces applied perpendicular to its longitudinal axis. The stresses induced due to the flexural load are combination of compressive and tensile stresses. For polymeric materials that break easily under flexural load, the specimen is deflected until rupture occurs in outer fibres. The effects of acetylation of flax on the flexural properties are given in Figure 8. The flexural strengths are found to be deliberately increased up to $18 \%$ degree of acetylation after that decreased rapidly with increasing degree of acetylation. The flexural modulus was also found to slightly increase up to $18 \%$ acetylation and then the property decreased slowly with increasing degree of acetylation. The improvement of flexural properties of treated fibre composites is likely to be due to removal of outer surface;

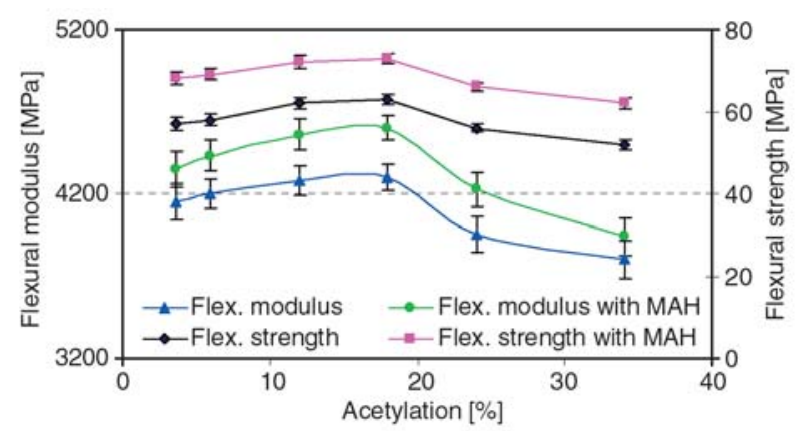

Figure 8. Influence of acetylation of flax fibre on flexural properties of composites increase cellulose content and effective surface area, increase interfacial adhesion and physical and chemical changes induced by fibre treatment. There is also fibrillation and diameter reduction of flax fibre due to acetylation that may have influence on modulus properties of composites. With increasing degree of acetylation the crack and damage of fibres were observed which may reduce the composites properties after certain range of acetylation. $\mathrm{MAH}$ has a positive influence on the flexural strengths and increased $20 \%$ maximum because of improvement of interfacial interaction. MAH has also some influence on the flexural modulus but the increase of flexural modulus was not prominent taking into account standard deviation.

\subsubsection{Charpy impact properties}

The impact strength of a composite is influenced by many factors, including the toughness properties of the reinforcement, the nature of interfacial region and frictional work involved in pulling out the fibre from the matrix. The nature of the interface region is of extreme importance in determining the toughness of the composite.

The notched Charpy impact strength of flax fibrePP composites with respect to degree of acetytion are presented in Figure 9. The Charpy impact test is a standardized high strain-rate test which determines the amount of energy absorbed by a material during fracture. This absorbed energy is a measure of a given material's toughness and acts as a tool to study brittle-ductile transition [21].

Ray et al. [22] observed that, in composites having weak interfacial bonding, the crack propagates along the fibre-matrix interface causing debonding. This leads to significant increase in the energyabsorbing capacity of the composites as a result of

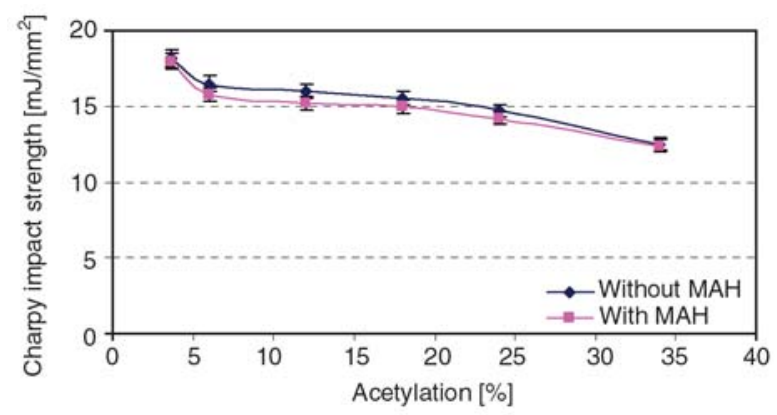

Figure 9. Influence of acetylation of flax fibre on charpy impact strength of composites 
the large new surfaces produced and frictional work resulting from differential displacement between matrix and fibre, which increases the impact fatigue resistance of the composites.

It was observed from diagram that the notched Charpy impact strength decreases slowly with increasing acetylation degree which is due to strong interface and decrease in toughness of composite [12]. No significant effect was observed by addition of MAH-PP, moreover impact properties were found to decrease a little bit. This could be explained by brittleness increase of matrix material and local internal deformation in composite material.

\section{Conclusions}

This study inspected the effect of acetylation of flax fibre on fibre properties and its reinforced polypropylene composites properties.

The following conclusions could be drawn:

- Small amount of catalyst content has a significant effect on reaction rate and degree of acetylation.

- Acetylation of flax fibres resists up to 50\% moisture absorption properties depending on degree of acetylation.

- Flax fibre morphology and components have been changed due to acetylation.

- Thermal stability increased till certain range due to acetylation.

- Highest tensile and flexural strength were scrutinized at $18 \%$ degree of acetylated flax fibre composites and about $25 \%$ improvement on strength properties was observed compare to untreated fibre composites.

- With the addition of MAH, the improvement of tensile strength of composites was observed 20 to $35 \%$ considering degree of acetylation.

\section{References}

[1] Li X., Tabil L. G., Panigrahi S.: Chemical treatments of natural fiber for use in natural fiber-reinforced composites: A review. Journal of Polymers and the Environment, 15, 25-33 (2007).

[2] Turmanova S. C., Genieva S. D., Dimitrova A. S., Vlaev L. T.: Non-isothermal degradation kinetics of filled with rise husk ash polypropene composites. Express Polymer Letters, 2,133-146 (2008).
[3] Mohanty A. K., Misra M., Drzal L. T.: Surface modifications of natural fibers and performance of the resulting biocomposites. Composite Interfaces, 8, 313-343 (2001).

[4] Bledzki A. K., Sperber V. E., Faruk O.: Natural and wood fibre reinforcement in polymers. Rapra Technology, Chesterfield (2002).

[5] Alvarez V. A., Ruscekaite R. A., Vazquez A. J.: Mechanical properties and water absorption behaviour of composites made from a biodegradable matrix and alkaline treated sisal fibres. Journal of Composite Materials, 37, 1575-1588 (2003).

[6] Frederick T. W., Norman W.: Natural fibers plastics and composites. Kluwer Academic Publishers, New York (2004).

[7] Rowell R. M., Young R. A., Rowell J. K.: Paper and composites from agro-based resources. CRC press, Boca Raton (1996).

[8] Akin D. E., Gamble G. R., Morrison W. H., Rigsby L. L.: Chemical and structure analysis of fibre and core tissues from flax. Journal of the Science of Food and Agriculture, 72, 155-165 (1996).

[9] Pizzi A., Eaton A.: The structure of cellulose by conformational analysis. Part 5. Cellulose II water sorption isotherm. Journal of Macromolecular Science, Part A: Pure and Applied Chemistry, 24, 1065-1084 (1987).

[10] Bledzki A. K., Gassan J.: Composites reinforced with cellulose based fibres. Progress in Polymer Science, 24, 221-274 (1999).

[11] Sreekala M. S., Thomas S.: Effect of fibre surface modification on water-sorption characteristics of oil palm fibres. Composites Science and Technology, 63, 861-869 (2003).

[12] Seena J., Koshy P., Thomas S.: The role of interfacial interactions on the mechanical properties of banana fibre reinforced phenol formaldehyde composites. Composite Interfaces, 12, 581-600 (2005).

[13] Mishra S. B., Luyt A. S.: Effect of organic peroxides on the morphological, thermal and tensile properties of EVA-organoclay nanocomposites. Express Polymer Letters, 2, 256-264 (2008).

[14] Joseph K., Paul A., Thomas S.: Effect of surface treatments on the electrical properties of low-density polyethylene composites reinforced with short sisal fibres. Composites Science and Technology, 57, 67-79 (1997).

[15] Mishra S., Misra M., Tripathy S. S., Nayak S. K., Mohanty A. K.: Graft copolymerization of acrylonitrile on chemically modified sisal fibres. Macromolecular Materials and Engineering, 286, 107-113 (2001).

[16] Lee S. M.: International encyclopaedia of composites, Vol. 4. VHC, New York (1991).

[17] Zafeiropoulos N. E., Williams D. R., Baillie C. A., Matthews F. L.: Development and investigation of surface treatments. Composites, Part A: Applied Science and Manufacturing, 33, 1083-1093 (2002).

[18] Sjorstrom E.: Wood chemistry: Fundamentals and applications. Academic Press, New York (1981). 
[19] Liu F. P., Wolcott M. P., Gardner D. J., Rials G. T.: Characterization of the interface between cellulose fibers and a thermoplastic matrix. Journal of Composite Interfaces, 2, 419-432 (1994).

[20] Tserki V., Zafeiropoulos N. E., Simon F., Panayiotou C.: A study of the effect of acetylation and propionylation surface treatments on natural fibres. Composites, Part A: Applied Science and Manufacturing, 36, 1110-1118 (2005).
[21] Bledzki A. K., Mamun A. A., Faruk O.: Abaca fibre reinforced PP composites and comparison with jute and flax fibre composites considering fibre contents. Express Polymer Letters, 1, 755-762 (2007).

[22] Ray D., Sarkar B. K., Rana A. K., Bose N. R.: The mechanical properties of vinylester resin matrix composites. Composites, Part A: Applied Science and Manufacturing, 32, 119-127 (2001). 